\title{
Addressing practical issues related to nursing care for international visitors to Hiroshima
}

\author{
PROBLEMAS PRÁTICOS RELACIONADOS AOS CUIDADOS DE ENFERMAGEM PARA \\ VISITANTES INTERNACIONAIS A HIROSHIMA
}

\section{CUESTIONES PRÁCTICAS RELACIONADAS CON LA ATENCIÓN DE ENFERMERÍA PARA VISITANTES INTERNACIONALES A HIROSHIMA}

\author{
Mariko Nishikawa' ${ }^{1}$, Kiyoka Niiya ${ }^{2}$, Masako Okayasu ${ }^{3}$
}

\section{ABSTRACT}

When nine million foreigners visited Japan in 2013, the federal government set a goal to attract an additional two and a half million visitors including medical tourists by 2020 . This research investigates the attitudes and concerns of Japanese nurses when they are in a situation dealing with foreign patients. The data were collected from March through September 2010, from 114 nurses at three hospitals, in close proximity to popular tourist destinations in Hiroshima. A questionnaire was developed for this research, named Mari Meter, which included a section to write answers to an open question for the nurses to express their opinions. These responses were examined statistically and by word analysis using Text Mining Studio. Japanese nurses expressed greatest concern about payment options, foreign language skills, and issues of informed consent, when dealing with foreigners. The results confirm that, in order to provide a high quality of patient care, extra preparation and a greater knowledge of international workers and visitors are required by nursing professionals in Japan.

\section{DESCRIPTORS}

Emigrants and immigrants

Patients

Health Services

Nursing care

Communication barriers

Japan

\section{RESUMO}

Quando nove milhões de estrangeiros visitaram o Japão em 2013, o governo federal estabeleceu uma meta de atrair outros dois milhões e meio de visitantes, incluindo o turismo médico, em 2020. Esta pesquisa investiga atitudes e preocupações de enfermeiras japonesas ao lidar com pacientes estrangeiros. Os dados foram coletados no período de março a setembro de 2010, com 114 enfermeiros de três hospitais próximos a destinos turísticos populares em Hiroshima. Um questionário denominado Mari Meter foi desenvolvido especificamente para esse fim, incluindo uma seção de respostas a uma questão aberta para que os enfermeiros expressem suas opiniões. As respostas foram submetidas a procedimentos estatísticos e de análise de discurso, usando o software Text Mining Studio. As enfermeiras japonesas expressaram maior preocupação quanto a opções de pagamento, conhecimentos de línguas estrangeiras e questões de consentimento informado, ao prestar cuidados a pacientes estrangeiros. Os resultados confirmam que, a fim de proporcionar um atendimento de qualidade ao paciente, é necessário preparação extra e maior conhecimento sobre trabalhadores e visitantes internacionais por parte de profissionais de enfermagem no Japão.

\section{DESCRITORES \\ Emigrantes e imigrantes \\ Pacientes \\ Serviços de Saúde \\ Cuidados de enfermagem \\ Barreiras de comunicação \\ Japão}

\section{RESUMEN}

Cuando nueve millones de extranjeros visitaron Japón en el año 2013, el gobierno federal estableció la meta de atraer al año 2020 a más de dos millones y medio de visitantes, incluyendo el turismo médico. Esta investigación analiza las actitudes y preocupaciones de enfermeras japonesas en el cuidado pacientes extranjeros. Los datos fueron recolectados entre marzo y septiembre del año 2010, por medio de entrevistas a 114 profesionales de enfermería de tres hospitales cercanos a zonas turísticas populares en Hiroshima. Se desarrolló específicamente para este fin un cuestionario llamado Mari Meter, con una sección con una pregunta abierta, para que las enfermeras expresan sus opiniones. Las respuestas fueron sometidas a procedimientos estadísticos y de análisis de discurso, utilizando el software Text Mining Studio. Las enfermeras japonesas expresaron su preocupación con respecto a las formas de pago, conocimientos de idiomas y tópicos del consentimiento informado mientras brindaban cuidados de enfermería a pacientes extranjeros. Los resultados confirman que para proporcionar una atención de calidad al paciente, los profesionales de enfermería en Japón necesitan de una preparación adicional y de un mayor conocimiento acerca de los trabajadores y visitantes internacionales.

\section{DESCRIPTORES \\ Emigrantes e inmigrantes \\ Pacientes \\ Servicios de Salud \\ Atención de enfermería \\ Barreras de comunicación \\ Japón}

\footnotetext{
${ }^{1}$ Master of Public Health, RN, Associate Professor, Department of Nursing, Faculty of Nursing, Hiroshima International University, Japan. mn378@ nyu.edu ${ }^{2}$ Mater Degree in Education, RN, Assistant Professor, Department of Nursing, Faculty of Nursing, Hiroshima International University, Japan. k-akutag@ns.hirokoku-u.ac.jp ${ }^{3}$ Mater Degree in Nursing, RN, Assistant Professor, Department of Nursing, Faculty of Nursing, University of Shimane, Japan. m-okayasu@izm.u-shimane.ac.jp
} 


\section{INTRODUCTION}

Although Japanese society is increasing its ethnic diversity through inter-marriage and bearing children with nonJapanese partners in recent years, the country remains an overwhelmingly homogeneous society. The nation had over 98\% Japanese ethnicity in $2010^{(1)}$. This makes the population know very little about foreigners despite the increasing number of non-Japanese residents and visitors.

Outsiders widely believe that the inheritance of centuries of tradition combined with a rigorous introspection and control, the enormous pressure to conform, and a fierce belief in cultural norms, makes Japanese accept that the suppression of the individual creates for the greater good of society. It is this notion, along with the Japanese culture, systems, structures and social mores that the casual outsider finds difficult to comprehend.

Being licensed nurses, the authors have experienced first hand the situation of dealing with foreign patients without any background information about them. In 2013, nearly nine million foreigners visited Japan, many of whom drawn by a federal government advertising campaign. Two million foreigners have registered to live in Japan as of $2010^{(1)}$. Furthermore, the government has set a goal to have 2.5 million additional tourists including medical tourists by $2020^{(2)}$. The number of foreign resident registrations has been increasing every year. Subsequently, foreigners account for $1.74 \%$ of the total 2013 population in Japan. In addition, the numbers of foreign students has grown sharply over the last decade ${ }^{(1)}$. These students use medical facilities when sick or injured as part of their leisure activities or part-time jobs ${ }^{(3-4)}$.

When a foreigner is admitted to a hospital in Japan, health-care workers often get anxious to provide the appropriate care to the patient ${ }^{(5)}$. This is particularly a concern of direct health providers. One study ${ }^{(5)}$ found that health-worker concerns comprised epidemiological emergencies, language barriers, culture differences and financial issues relating to health insurance. There are a few studies documenting these concerns of nurses who care for foreign patients ${ }^{(6)}$, but their findings are not widely applicable in different parts of the country.

This research investigates the concerns of nurses while attending to international patients in Hiroshima. To understand the problems encountered by Japanese nurses when taking care of foreign patients, we analyzed their responses to an open-ended question. The next section of this article describes the method of data collection and analysis. This is followed by a description of the results and our analyses.

We expect our findings will contribute to both the preparation and care of the patients within the country, while providing information about the current situation of Japan internationally.
METHOD

\section{Population and sampling procedures}

The research design of this pilot study was approved both by the Hiroshima International University Ethics Committee and by Shimura Hospital in Hiroshima. We approached the nurses, explained the objectives, assured data confidentiality as well as anonymity, and requested their written consent. The participants were sampled based upon their willingness to cooperate and answer the questionnaire. Data collection was carried out from March 2010 through September 2010. A questionnaire and survey was distributed to participants to be collected within a month.

One hundred fourteen nurses out of 184 who were asked, participated in this survey. The nurses who answered the survey either provided patient-care directly or supervised junior nurses at hospitals. The participants had neither taken any courses on international relations and culture nor had any background on global health, as part of their education. They had never attended classes or given briefings related to taking care of foreigners. Such classes are still uncommon in the Japanese nursing curriculum ${ }^{(7)}$. The participants only speak Japanese and possess no other second language proficiency. The ethnic background of all the participants was Japanese.

\section{The research tool}

The questionnaire was developed based on the literature reviewed ${ }^{(4-6-8)}$ following which, a pilot test was administered. The questionnaire has three parts: a 9-item section for demographic questions; a blank sheet for an open-ended question; and another 15-question section.

The first part of questionnaire collected demographic information: age, gender, profession, final education, current position, current ward, year of nursing job, experience taking care of foreigners, and the proficiency of language to take care of them.

In the second part, a sentence read: Could you please imagine and write down whatever responsibilities you require to take care of a foreigner in your hospital today? Your opinions will be most useful when you write as much as possible.

The third part of the questionnaire, named Mari Meter, collected data from those who cared for patients directly. At the top of the 15 -item questionnaire, two sentences read: Listed below are issues that concern some but not all nurses. Please read each statement and CIRCLE the response that best suits your experience.

The fifteen items included: choose a hospital, pay medical expenses, language communication, eye contact, contents of the medicine, quality of medical care, quality of nursing care, pick up an infection, protection 
of privacy, lifestyle difference, emergency care, medical system, direction in a hospital, dealing with medical staff and informed consent by 5-point Likert-scale. The 5-point scales are: Not at all concerned; Not very concerned; Neutral; Somewhat concerned; and Very concerned.

\section{Demography of participants}

The characteristics of the participants were summarized in Table 1.

Information written on a blank sheet of paper was examined by word-requests analysis, by word relationship network and through co-occurrence by a language analysis software, called Text Mining Studio, version3.2 ${ }^{(9)}$.

Text mining analysis is a technique to extract information from document collection ${ }^{(10)}$. The idea behind text mining is to dig up key hidden information after the meaning of a sentence from its words. In order to avoid misunderstanding the results, it is necessary to read the full text carefully, prior to making any judgments. We analyzed the text by word frequency analysis, especially their requests, and word relationship network.

A horizontal bar graph with descriptive statistics shows the responses related to health care of foreigners. The reliability of the 15 -items questionnaire was examined by Cronbach's alpha. The relationship between those with experience taking care of foreigners and those without experience was analyzed by categorical logistic regression. The above statistical analyses were conducted using the JMP statistical package (version 9.0).

\section{Results from Numeral Data}

\section{Personal and Characteristics of Nurses}

Table 1 shows our research participants numbered 114 out of 184 nurses (response rate of 63\%), ages ranged from 20 to over 60 (mode 30-39). The majority of the nurses were female $(97.4 \%, 111)$ compared to 3 males. Their educational backgrounds spanned from a two-year nursing school completion (34.2\%, 39), three-years nursing school diploma $(61.4 \%, 70)$ to a university degree $(4.4 \%, 5)$.

The participants of our research who held a university degree correlated with the size of hospitals in Hiroshima. Their professions were: Registered Nurses - RN $(65.8 \%, 75)$, and Licensed Practitional Nurses - LPN (34.2\%, 39). The ratio of RN to LPN is similar to that of Hiroshima prefecture with the scale of hospitals. Their current job positions were: chief nurse or higher (8.8\%) and staff nurses (91.2\%). Although this study includes administration nurses, they too provided direct heath care at their hospitals. The number of beds in their hospitals ranged between 70 and 130 . Their median length of work experience was 10-19 years, and ranged from 4 months to 40 years. More than twenty foreign patients visited their hospitals each year with increasing numbers during 2010 to 2013.

\section{Previous Experience with Foreigner care}

Of the respondents, many of the participants, 76 out of one 114 had experience to take care of foreign patients. Their experience in wards were; inpatient unit (81.6\%), outpatient unit (13.1\%), ICU (I.8\%), and others (3.5\%). Consequently, the majority of the nurses took care of foreigners at inpatient units (see Table 1).

Table 1 - Baseline characteristics for all participants

\begin{tabular}{|c|c|c|c|c|}
\hline Variable & & $\%$ & (n) & MD \\
\hline Age & & & (114) & $30-39$ \\
\hline \multirow[t]{2}{*}{ Gender } & Female & 97.4 & (111) & \\
\hline & Male & 2.6 & (3) & \\
\hline \multirow[t]{2}{*}{ Profession } & Nurse(RN) & 65.8 & $(75)$ & \\
\hline & Nurse(LPN) & 34.2 & (39) & \\
\hline \multirow[t]{3}{*}{ Education } & Bachelor degree & 4.4 & $(5)$ & \\
\hline & RN diploma (3-year) & 61.4 & $(70)$ & \\
\hline & LPN diploma (2-year) & 34.2 & (39) & \\
\hline \multirow[t]{2}{*}{ Current position } & Chief nurse or more & 8.8 & $(10)$ & \\
\hline & Staff nurse & 91.2 & (104) & \\
\hline \multirow[t]{4}{*}{ Current ward } & In patient unit & 81.6 & $(93)$ & \\
\hline & Outpatient unit & 13.1 & $(15)$ & \\
\hline & ICU & 1.8 & (2) & \\
\hline & Others & 3.5 & (4) & \\
\hline Work experience (year) & & & (114) & $10-19$ \\
\hline \multirow[t]{2}{*}{ Experience of foreigner care } & Yes & 66.7 & $(76)$ & \\
\hline & No & 33.3 & $(38)$ & \\
\hline \multirow[t]{4}{*}{ Ward of the care for foreigner } & In patient unit & 81.6 & $(93)$ & \\
\hline & Outpatient unit & 13.1 & $(15)$ & \\
\hline & ICU & 1.8 & (2) & \\
\hline & Others & 3.5 & (4) & \\
\hline
\end{tabular}

$(n=14) M D=$ median

Addressing practical issues related to nursing care for international visitors to Hiroshima Nishikawa M, Niiya K, Okayasu M 


\section{Results from the open-ended question}

\section{Basic information}

A summary of the descriptive statistics of the openended question is: mean of number of letters written for each participant 43.1; total sentences 309; mean of letters in length of sentences 162; and, a total of 1925 words.

\section{Requests from nurses}

Table 2 shows the requests from nurses when taking care of foreigners at their hospitals. This was analyzed by word frequency analysis. The nurses were concerned about; contact, explain, relationship, communication, writing, callout, correspond, bring words, receive and understand. Those ten words appear from 1925 words as important demands for looking after the patients.

Table 2 - Requests from nurses

\begin{tabular}{lc}
\hline \multicolumn{1}{c}{ Requests } & Parts of speech \\
\hline contact & noun \\
explain & noun \\
relate & verb \\
communication & noun \\
write & verb \\
call out & noun \\
correspond & noun \\
bring word & verb+noun \\
receive & verb \\
understanding & noun \\
\hline
\end{tabular}

Note: $(n=114)$

\section{Word Relationship Network: co-occurrence}

The nurses' concerns were analyzed using a network graph of words shown in Figure 1. The word-network was derived using the total number of words from each of the individual participants. It shows how a word is related to other words, particularly the word at the center of the main circle. The main word is the keyword. The size of circles shows the ratio of the frequency of words. The large size circles show words appearing at a greater frequency. The thickness of the line depicts the strength of the association between words. Thick lines indicate a stronger association between words. In this manner, we can visually assess the clusters. The full text analyses further supports our results.

The concerns have five clusters from alphabet letters $A$ to $E$. The authors interpreted those clusters as: A language, B life style difference, C communication, D thinking, and $\mathrm{E}$ interpreting cluster. In $\mathrm{A}$, language is related with; need, nursing, speak, contact, proficient, get across, cannot get across, understand, not understand, do country, big, barrier and problem. B life style difference shows a relationship to; culture, uneasy, wish to tell, conversation, difficulty and not understand. C communication involves; patient can get, not understand, religion, hand gesture and body gesture. $D$ thinking contains; can do, symptom, explain, correspondence and difficult. Interpreting cluster E has; people, exist, need and interpreting. Cluster $\mathrm{A}$, language, contains many more words than other clusters.

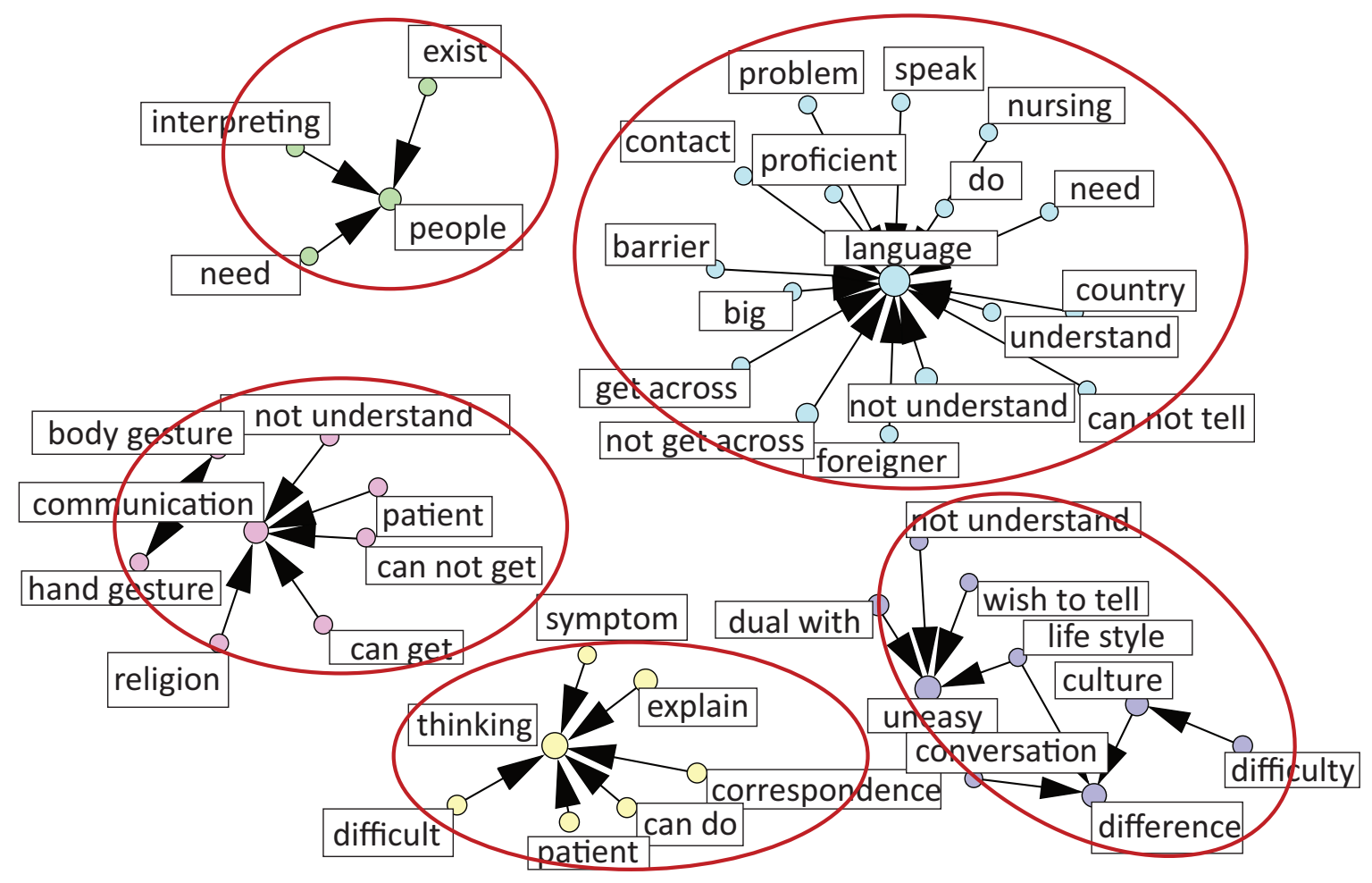

Figure 1 - Word relationship network: co-occurrence. 


\section{Health care concerns}

The nurses' concerns are shown in Figure 2. Overall, 15-ite$\mathrm{ms}$ in the questionnaire were responded to by using the very concerned and somewhat concerned options (more than fifty percent is shown with dark colors). Concerning Heath care for Foreigner shows a high score. At the higher concern level, seven out of fifteen are; payment of medication expenses, language communication, informed consent, chooses hospital, lifestyle difference, contents of the medicine, and dealing with medical staff. Particularly, the payment of medication expenses, language communication and informed consent fall above eighty percent of the nurses' responses identified as either very concerned or somewhat concerned.

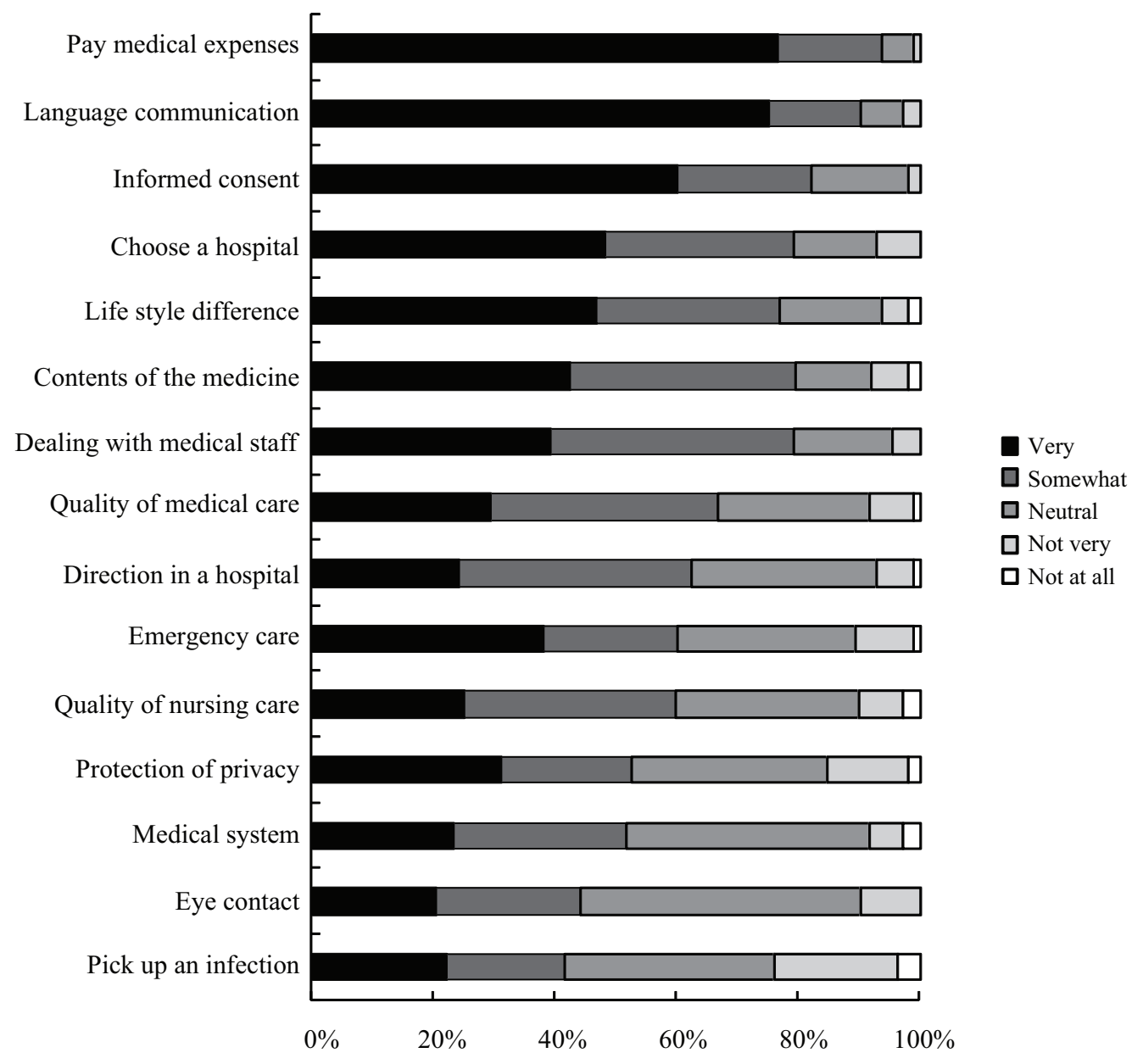

Figure 2 - Concerning for taking care of foreigners.

\section{Reliability}

The reliability of the 15 multi-item questions (Mari Meter) was confirmed by Cronbach's alpha internal consistency reliability coefficient of 0.89 . It shows that the questionnaire has a high reliability.

\section{Regression analysis}

In the categorical logistic regression method, we aim for the analysis to predict whether nurses in the yes or no to take care of foreigners at their hospitals, is a concern to the third part of the Mari Meter questionnaire. The reason being a difference between the nurses who have already taken care of foreign patients or those that did not. The concerns from the experienced nurses might be more desirable and realistic. The following hypotheses were set.
- HO: There is no relationship between having experience taking care of foreigners and Mari Meter.

- $\mathrm{H} 1$ : There is a relationship between experience caring foreigners and Mari Meter.

We found that there is a relationship between yes and no to take care of foreigners with four items significance; informed consent and life style difference $(p<0.0 l)$, directions in a hospital and eye contact $(P<0.05)$. In the categorical logistic regression, $P<0.20$ are taken to have a relationship; medical system (See Table 3). Out of the fifteen items, ten were excluded. The nurses with experience taking care of a foreigner have a greater concern about informed consent and the nurses whose have not have the experience have other four items of concern. 
Table 3 - Experience for taking care of foreigners by categorical logistic regression

\begin{tabular}{lcccccccc}
\hline \multirow{2}{*}{ Items } & \multicolumn{3}{c}{ Experience group n=76 } & \multicolumn{3}{c}{ Inexperience group n=38 } \\
\cline { 2 - 8 } & Mean & SD & $\mathbf{9 5 \% \mathbf { C l }}$ & Mean & SD & $\mathbf{9 5 \%} \mathbf{C l}$ & P-value \\
\hline Informed consent & 4.47 & 0.79 & $4.65-4.29$ & 4.27 & 0.87 & $4.56-3.98$ & $0.0002 * *$ \\
Life Style Difference & 4.05 & 1.01 & $4.28-3.82$ & 4.38 & 0.89 & $4.68-4.08$ & $0.0081^{* *}$ \\
Directions in a hospital & 3.68 & 0.90 & $3.89-3.48$ & 4.00 & 0.93 & $4.31-3.69$ & $0.0117 *$ \\
Eye contact & 3.42 & 0.91 & $3.63-3.21$ & 3.81 & 0.91 & $4.11-3.51$ & $0.0457 *$ \\
Medical System & 3.60 & 1.01 & $3.83-3.37$ & 3.73 & 0.93 & $4.04-3.42$ & 0.1018 \\
\hline
\end{tabular}

${ }^{*} p<0.05{ }^{* *} p<0.001$. Note: $(n=114)$

\section{DISCUSSION}

The provision of equal care to all patient subjects regardless of nationalities is a tenet upheld nationwide, by the Japan Nursing Association. As a consequence, human rights and ethical considerations are required to be of the highest standard among Japanese nurses.

As shown in the horizontal bar graph (Figure 2), the nurses' concerns were very high to take care of foreigners. The nurses' higher concerns indicated by somewhat and very concerned were; payment of medical expenses, foreign language communication, informed consent, choose a hospital, and life style difference. In particular, payment of medical expenses and foreign language communication totaled 90 percent of the nurses' responses using very concerned.

We found the nurses were just as strongly concerned about payment in this study. This is similar to other research results ${ }^{(5-6,8)}$. The reason might be that Japanese patients are usually covered by at least one union, which is either the national health insurance or the social health insurance. Additionally, some Japanese nationals hold private health insurance. Their insurance will cover from $70 \%$ up to $100 \%$, depending on the coverage policy with any medical care. On the other hand, the method of payment for medical services from foreign patients are unknown and there is no guarantee that they are insured. Only a few Japanese nurses, who participated in this research, were familiar with hospital administration.

In 2013, there has been an increase in the number of foreign visitors and international students to Hiroshima. Compounding the cultural problems are the dress codes and manners of foreign patients. Marmot ${ }^{(11)}$ and Bhopal ${ }^{(12)}$ have analyzed ethnic inequalities in health and health care within a single country.

Similar to these studies, we found that different appearances lead to the financial concerns. Some nurses are worried because the cost of medical care can be expensive in Japan. Some of the foreign patients, particularly those from developing nations, may not have the financial resources.

Even if a foreigner does not carry any insurance, Japanese hospitals often do not refuse treatment to the patient because of human rights. This subsequently results in financial problems with the foreign patient. Taking care of several foreign patients could have a negative impact on the economic situation of a small clinic or a local hospital, particularly if tourists fall sick during their travels and are without any insurance.

As an example, the Narita Red Cross hospital located near Tokyo International Airport, frequently takes care of foreigners whose treatments include operations and admittance to the ICU/CCU. The average length of the hospital stay was 10.8 days. The hospital did not receive $35 \%$ of their dues for services rendered in 2000. In another instance, a patient was unable to cover his/her medical expense, despite a promise to pay 5,000 Japanese yen each month for total amount of 700,000 yen $^{(5)}$ (One USD is equivalent to 82 Japanese yen at the time of this study in December 2012).

Language and communication are also rank as high concerns in figures $I$ and 2 . There are some studies showing how Japanese health care workers struggle to communicate with foreign patients $s^{(5-6)}$. There are similar findings in other nations, such as Sweden ${ }^{(13)}$.

As we mentioned at beginning of this paper, the nation has $98 \%$ Japanese ethnicity who do not speak a foreign language often, even though many are taught English since junior high school. Moreover it is not known which language foreigners understand. Those circumstances increase stress level of nurses who have a strong responsibility to take care of the patients directly.

Interpreters are often needed for foreign patients. Although some are available, (circle E in figure 1 ), it is difficult to have interpreters constantly provide timely service to both patients and care providers. Hence, nurses use hand gestures to communicate with foreign patients (circle C). Some hospitals prepare interpreters and foreign language brochures for their patients, but both have limited effectivenes ${ }^{(5)}$.

The majority of Japanese hospitals do not have interview papers and informed consent forms in foreign languages. Nurses also need to know various vocabularies that relate to daily tasks in hospitals. Although the nurses looking after the patients (circle D) understand 
the symptoms, they find it difficult explain those symptoms to the patient. In those circumstances, health care workers, including nurses take both extra time and additional care ${ }^{(5,8)}$.

Having informed consent before patient-care is an important step in current medical practices. However, the majority of hospitals in Hiroshima do not provide informed consent forms in foreign languages. Usually, the medical professionals first explain the process, and then get the signature or seal from the patients in Japan. Without the form, they cannot proceed to the next step.

Presently, nurses are required to clearly explain to patients before providing any medical and nursing care in Japan. It is vital to be confident to consider the safety and ramifications of the patient. Only after few days of foreign patients being admitted, do nurses get their message across with hand and body gestures. Some patients speak Japanese, but that does not help to get informed consent because special vocabularies are used in the form. Thus, nurses are looking for timely interpretation before providing care.

In categorical logistic regression, we examine whether the concerns might be different between the nurses who took care of foreigners against those who have not. There is a difference between yes and no to taking care of foreigners with four items significance $(p<0.05)$ and one item is $p<0.20$. They are informed consent, life style difference, direction within a hospital, and eye contact. The nurses whose were experience to take care of foreigners were more concerned about informed consent, and the nurses whose have not have the experience have four other items. The reasons might relate to experienced nurses getting consent from the patient for treatment. The vocabularies are incompatible to communicate using hand and body gestures. Furthermore, the nurses want to have confidential agreements.

The choice of a hospital is also a high concern. When foreign patients require a suggestion of hospitals, it is not easy for the nurses to provide them a clear answer. Japan does not have a regular system of hospital networks capable of accepting foreign patients. For example, when one foreign tourist had a skin irritation from a mosquito bite while visiting to a bamboo thicket, he/she found it difficult to reach the appropriate health-care facility. She asked the tourist information desk for a hospital. She was also looking for a person who speaks English or Spanish for assistance. On that particular day, none of the in-town hospitals or clinics treated her because they were not prepared for foreigners at that time. Often, there are no foreign language services available for their special needs. Even if the patient received medical care at a hospital and then need to move to another area, it will be more difficult to provide alternate hospital choices. This issue does not arise with local Japanese patients.
Some Japanese nurses are concerned about life style difference associated with foreign patients. The nurses feel uneasy to care for foreigners with culturally appropriate methods compared to local patients. Generally, we know that there are differences with; health attitude and behavior, expressing the tolerance of pain, and food preferences ${ }^{(4,6,14)}$ when compared to local patients.

In this study nearly eighty percent of the nurses are very and somewhat concerned about life style differences (Figure 2). Their feelings associated to culture are reflected in Circle B (figure 1). Life style and culture are both different and equally difficult to understand. One example of the difficulties of managing different cultures was encountered when a foreigner was admitted to one hospital included in this study. His roommate complained to the nurses about the foreigner's food having a strong aroma and that the foreigner had too many friends visiting the room. His roommate was uncomfortable to stay in the same room. In another example, a foreigner, showed exaggerated emotional expression. That seems overwhelming to Japanese cultures. Nevertheless in the globally interconnected world of the future, Japan should further adjust to other cultures and life styles. Some of nurses were worried about the smaller size of Japanese medical facilities. In nations such as Canada ${ }^{(15-16)}$, Sweden $^{(12,17)}$, and Norway ${ }^{(18)}$, researchers found that nurses must adjust to provide culturally safe care to immigrant patients.

The content and quality of the medicine also reveal a high concerning score. However, the quality of nursing care is less of a concern. The reason is that medical care is more likely to affect the patients' life, death, and safety. The nurses have a big responsibility to provide medical care daily. This circumstance gives the nurses more tension. In both medical and nursing care, the nurses wonder if there may be a different way to provide health-care.

Dealing with medical staff is also a concern to the nurses. Japanese nurses place strong emphasis on the quality of patient care, as mentioned ealier. Ethnically, Japan still remains a homogeneous society. Many Japanese do not have exposure to other nationalities, particularly around the Hiroshima area, despite the numerous tourists.

Lastly, the pick-up of an infection scored the lowest concern out of the fifteen items. The nurses seem confident to protect themselves from the infection of foreign patients. This is because there are strong hospital policies that are routinely followed when dealing with infections.

In summary, there remain challenges to provide uniform care to foreign patients as with local patients. A survey ${ }^{(19)}$ revealed that immigrants were at a disadvantage for psychiatric inpatient care. In Geneva, Switzerland, it is not easy to prepare professional interpreters for patients who are not French speakers ${ }^{(20)}$. Although it is challenging to deal with foreign patients, the nursing profession needs to continue to make a greater effort.
Addressing practical issues related to nursing care for international visitors to Hiroshima Nishikawa M, Niiya K, Okayasu M 
One limitation of this study is an undefined target population for foreign patients. For example, medicalcare requirements may be different for tourists, foreign students, and immigrants. Among tourists there is little health-related information because they are far from their families. The health status of the patient is important because health care is related to a patient's medical history. This concept is not analyzed in our study. Our survey did not include the time of the year when nurses take care of foreigners, as it might lead to biases.

\section{CONCLUSION}

The government of Japan has a goal of increasing the number of foreign tourists each year. Although the numbers of tourists have grown sharply, only a few studies have examined the problems encountered by nurses whom have taken care of foreign patients. When providing highquality clinical health care to them, local nurses need to deal with communication and cultural differences.

Without adequate education and training for taking care of foreigners, Japanese nurses will find working with international patients to be a difficult experience. Based on our findings, we provide the following suggestions for nursing profession in Japan; (a) understand their financial status, (b) gain knowledge of foreign patients through continued education, (c) provide information of the Japanese health system including hospital information to foreigners. These results suggest that in order to take care of foreign patients better, a comprehensive response dealing with nurses' highest concerns is vital for the health staff at Japanese facilities.

\section{REFERENCES}

1. Japan. Ministry of Justice. The statistics in foreign registrants in 2010 [Internet]. Japanese; 2010 [cited 2012 Dec 7]. Available from: http://www.moj.go.jp/nyuukokukanri/kouhou/ press_090710-1_090710-1.html

2. Japan. Tourism Agency Ministry Land, Infrastructure, Transport and Tourisms. Nation tourism promotion basic plan in 2010 [Internet]. Japanese; 2010 [cited 2012 Dec 7]. Available from: http://www.mlit.go.jp/common/000125458.pdf

3. Nishikawa M, Kume A. Migration Health of the Foreign Students in Japan: An interpretative case study. In: Proceedings of the XVII the International Congress for Tropical Medicine and Malaria; 2008; Jeju, Korea.

4. Kume A, Nishikawa, Okubo I. Survey on health behavior of Chinese foreign students in Japan compared with domestic students. J Int Health. 2010;25(3): 171-9

5. Osegawa $M$, Morio $H$, Nomot $K$, Nishizawa $M$, Sadahiro $T$. Present medical practice and problems in emergency disease in foreign travelers requiring admission. Japan Emerg Med J. 2002;13(11):703-10.

6. Hashegawa T, Takeda C, Tsukida K, Shirakawa K. A study of nursing care for foreigners in Japan. J Fukui Med Univ. 2002;3(1-2):49-55

7. Nishikawa M, Kume A, Akutagawa K. Effectiveness of Study Abroad Programs for Nursing Students in Japan. In: Proceedings of the Council of Nurses (ICN) 24th Quadrennial Congress; 2009 April 29-May 3; Durban, South Africa [CD-ROM].

8. Yamagishi S, Sakuma Y, Miyauchi K, Matsumoto A, Horikawa $S$, Shibui $Y$, et al. The anxiety for medical services system in inbound tourists to Japan. J Int Health. 2008;23(4):273-9.
9. Mathematical System. The Text Mining Studio Manual 3.2. Tokyo: Mathematical System Inc; 2010.

10. Feldman R, Sanger J. The text mining handbook: advanced approches in analyzing unstructured data. Cambridge; Cambridge University Press; 2007.

11. Marmot M. Achieving health equity: from root causes to fair outcomes. Lancet. 2007;370(9593):1153-63.

12. Bhopal SR. Ethnicity, race, and health in multicultural societies. Great Clarendon St.: Oxford University Press; 2007.

13. Wiking E, Saleh-Stattin N, Johansson SE, Sundquist J. Immigrant patients' experiences and reflections pertaining to the consultation: a study on patients from Chile, Iran and Turkey in primary health care in Stockholm, Sweden. Scand J Caring Sci. 2009;23(2):290-7.

14. Nishikawa M, Yokoyama H. Challenges of nursing in a multicultural society: Australia. Nurs J Hiroshima Int Univ. 2011;8(1):71-9.

15. Grewal SK, Bhagat R, Balneaves LG. Prenatal beliefs and practices of immigrant Punjabi women living in Canada. J Obstet Gynecol Neonatal Nursing . 2008;37(3):290-300.

16. Weerasinghe $\mathrm{S}$, Mitchell $\mathrm{T}$. Connection between the meaning of health and interaction with health professionals: caring for immigrant women. Health Care Women Int. 2007;28(4):309-28.

17. Hultsjö S, Hjelm K. Immigrants in emergency care: Swedish health care staff's experiences. Int Nurs Rev. 2009;52(4):276-85.

18. Samarasinghe K, Fridlund B, Arvidsson B. Primary health care nurses' promotion of involuntary migrant families' health. Int Nurs Rev. 2010;57(2): 224-31. 
19. Lay B, Lauber C, Nordt C, Rössler W. Patterns of inpatient care for immigrants in Switzerland. Soc Psychiatry Psychiatr Epidemiol. 2006;41(3):199-207.
20. Hudelson P, Vilpert S. Overcoming language barriers with foreign-language speaking patients: a survey to investigate intra-hospital variation in attitudes and practices. BMC Health Serv Res. 2009;9:187.

\section{Acknowledgements}

We are grateful to the participants in our study and to those who collected the data at three hospitals in Hiroshima. Funding for this study was obtained from the Japanese Government Grant-in-Aid for Challenging Exploratory Research 2010-2013. 